EESTI NSV TEADUSTE AKADEEMIA TOIMETISED. 20. KÖIDË

KEEMIA * GEOLOOGIA. 197I, NR. 4

ИЗВЕСТИЯ АКАДЕМИИ НАУК ЭСТОНСКОЙ ССР. ТОМ 20

ХИМИЯ * ГЕОЛОГИЯ. 1971, Nㅜ 4

удК 547.541 .5

РЕЭТ ПРИИМАН, М. ГУБЕРГРИЦ

\title{
МАКРОКИНЕТИКА АКТИВИРОВАННОГО ОКИСЛЕНИЯ АЛКИЛАРИЛСУЛЬФОНАТОВ
}

Процесс окисления алкиларилсульфонатов (ААС) в токе кислорода, активированный добавкой соли железа и перекиси водорода (модифицированный реактив Фентона), изучен на двух специально синтезирован ных модельных веществах - натриевой соли изопропил- и $\boldsymbol{H}$-гептил-бензолсульфоната. Наличие в молекуле ААС сульфогруппы, как известно, резко подавляет реакционную способность наиболее активного атома углерода - из алкильной цепи в $\alpha$-положении относительно бензольного кольца. Добавка двухвалентного железа и перекиси водорода, по лите ратурным данным, не катализирует процесс окисления, но взаимодействие их приводит к образованию свободных радикалов $\mathrm{HO}_{2}^{*}$ и $\mathrm{OH}^{\prime}$; последний известен как чрезвычайно сильный окислитель [1].

Эксперимент призван имитировать окислительную деградацию технических поверхностноактивных веществ (ПАВ), и поэтому проведен со смесью чистого AAC (35 вес. \%) с сульфатом натрия х.ч. (65\%) как наполнителя. Для синтеза АAC использованы тщательно очищенные кумол и специально синтезированный $t$-гептилбензол, т. е. смесь изомеров с различным расположением бензольного ядра в линейной алкильной цепи. Преобладание в ней изомеров (около 90\%) 2-, 3- и 4- с близкими свойствами и сходной реакционной способностью предотвращает внесение чрезмерной погрешности в результаты макрокинетического эксперимента. Использованная методика сульфонирования алкилбензолов обеспечивает получение продукта с сульфогруппой в пара-положении относительно алкильной цепи.

Эксперимент проведен с водными растворами АAC при концентрации 1,75 г/л и рН 4,0 в стеклянной окислительной ячейке широко распространенной конструкцни $\left[{ }^{2}\right]$ в ультратермостате в температурном интервале от 20 до $70 \pm 0,1^{\circ} \mathrm{C}$. В растворе АAС фиксируются: изменение концентра ции исходного АAC (по комплексообразованию с метиленовым голубым в хлороформе); количество химически связанного кислорода (по специально разработанной нами методике применительно к АAC [3]); кон . центрация в реакционной смеси кислородных функциональных групп (суммарной карбонильной и сложноэфирной, гидроксильной, карбоксильной, гидроперекисной и перекисной - обычными методами функіционального анализа); содержание фенолов (по комплексообразованию с 4-аминоантипирином), ненасыщенных - по бромному числу. Описанная методика использована ранее в эталонном исследовании (в той же установке) по аутоокислению кумола, результаты которого удовлетворительно отвечают опубликованным ранее в литературе [ $\left.{ }^{2}\right]$. Опыты проводи- 
лись до достижения степени превращения исходного АAC не менее $20 \%$, а при темпеpatype $50^{\circ}$ и выше - до $50-70 \%$.

В результате эксперимента установлено, что выход продуктов побочных реакций - фенолов и олефін нов - во всех случаях в пределах точности эксперимента отсутствует. Непосредственная идентификация в реакционной смеси малостабильной гидроперекиси АAC практически оказывается невозможной вследствие чрезвычайно быстрого образования ею комплекса с ионами железа (см. ниже) и столь же быстрого ее распада. В обоих циклах продукты окисления, характеризуемые с помощью функционального анализа, представляют собой исключительно соединения ¿ карбонильными функциями - кетоны и сложные эфиры. При окислении изопропилбензолсульфоната доля связанного кислорода, входящего в состав указанных групп (25-35\% от суммарно поглощенного количества), сравнительно мало изменяется во времени и почти не зависит от температуры. B опытах с производным $H$-гептилбензола измененне ее во времени при заданной температуре практически не происходит, а абсолютное значение возрастает с повышением температуры. Доля же сложноэфирных групп в сумме карбонильных функций во всех случаях для обоих ААС устойчиво составляет $30-35 \%$.

На рис. $1-4$ графически интерпретирована макрокинетика деградации обоих АAC: по превращению исходного вещества, поглощению кислорода (в расчете на 1 моль деградировавшего ААС), расходу в процессе перекиси водорода и формированию продуктов с карбонильными группами. Поглощение кислорода и накопление в системе кетонов и сложныж эфиров протекает монотонно, по линейному закону, причем скорость и глубина суммарного окислительного превращения, очевидно, не снижаются по исчерпании ресурсов перекиси водорода в системе. Подчерк- 


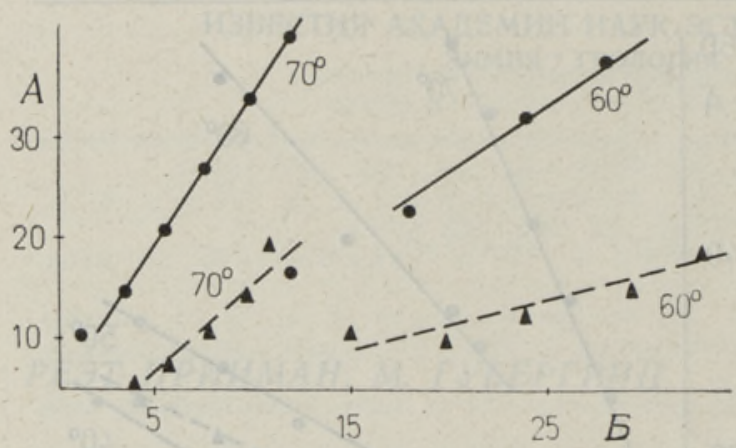

Рис. 3. Қинетика накопления суммы карбонильных групп в процессе окисления $\boldsymbol{H}$-гептил- (•) и изопропилбензолсульфонатов (•). $A$ - доля соединений с карбоннльными группамн от исходного реагента, моль. \%, $b$ - длительность олыта, 4 .

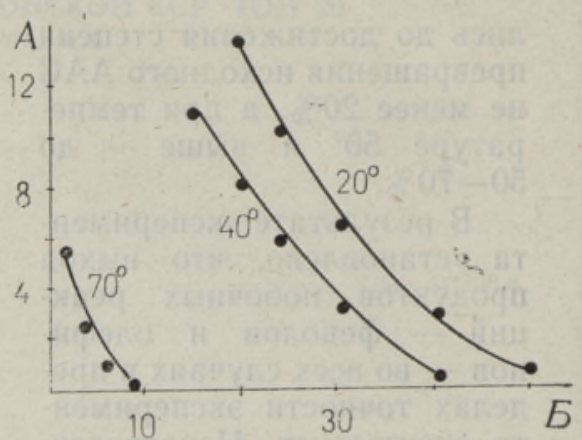

Рис. 4. Изменение концентрации пере. киси водорода в реакционной смеси изопропилбензолсульфоната.

$A$ - остаток перекиси водорода, \% от изходного, $Б$ - длительность опьта, 4 .

нем также, что значение $\mathrm{pH}$ медленно, но неизменно, возрастает с повышением степени деградации исходного АAC (ориентировочно от 4,0 до $4,4-4,3)$.

Анализ экспериментальных данных приводит к заключению, что активированное окисление АAC в подобного рода системе протекает в нескольких последовательных стадиях, первая из которых соответствует схеме, принятой обычно для аутоокисления алкилбензолов [4, 5]:

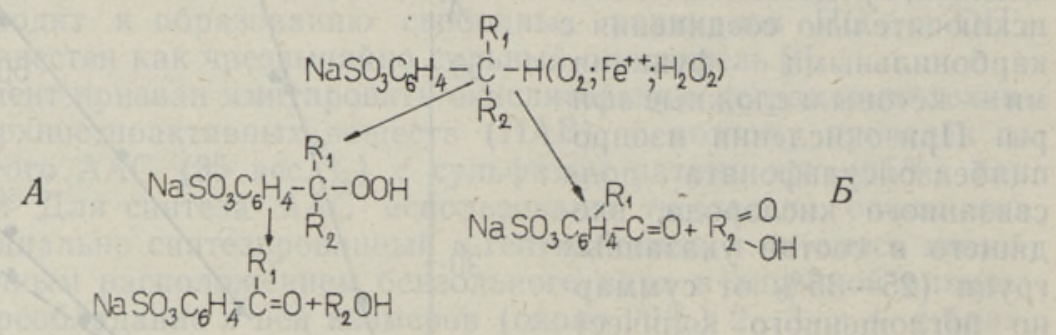

На этой стадии протекают параллельные реакции $(A$ и $Б)$ образования гидроперекиси с последующим ее распадом до сульфоарилкетона и алифатического спирта, а также непосредственного окисления АAC до первичного кетона и карбоновой кислоты. Взаимодействие полученных спиртов и кислот завершает первую стадию образованием сложных эфиров. Поскольку выход продуктов реакции $Б$ эквимолярен и в системе не установлено накопление ни гидроксильных групп, ни кислых компонентов, скорость параллельных реакций $A$ и 5 можно считать равной, а большую часть карбонильных соединений в составе реакционной смеси отнести к продуктам вторичного, более глубокого окисления.

Судя по данным, полученным для окисления изопропилбензолсульфоната - гомолога с необъемистым алкильным заместителем, наряду с образованием промежуточных алкилароматических кетонов неизвестного строения на второй стадии, частично происходит раскрытие бензольного кольца и отрыв сульфогруппы с окислением ее до сульфатной. Результаты ориентировочного расчета показывают, что количественная харак теристика этого явления (выход продуктов глубокой деструкции равен $60-65 \%$ от деградировавшего АAC) совпадает с литературными данными для биодеградации алкиларилсульфонатов [ $\left.{ }^{6}\right]$.

Тем не менее, накопленный экспериментальный материал дает осно- 
вание считать, что механизм превращений на первой стадии суммарного процесса существенно отличается от известного из литературы. В системе в присутствии кислорода протекает комплекс реакций с образованием не только радикалов гидроксила или $\mathrm{HO}_{2}$, но и с накоплением перекисных и других органических радикальных продуктов, а также гидроперекисей, которые в свою очередь при взаимодействии с ионами железа пополняют ресурсы активных частиц:

$$
\begin{aligned}
& \mathrm{ArRH}+\mathrm{OH}^{*} \rightarrow \mathrm{ArR}^{*}+\mathrm{H}_{2} \mathrm{O} ; \text { ArR }+\mathrm{O}_{2} \rightarrow \mathrm{ArRO}^{*} ; \mathrm{ArROO}+\mathrm{RH} \rightarrow \\
& \rightarrow \mathrm{ArRO}_{2} \mathrm{H}+\mathrm{R}^{*} \text {; } \\
& \mathrm{ArRO}_{2} \mathrm{H}+\mathrm{Fe}^{2+} \rightarrow \mathrm{ArRO}^{\circ}+\mathrm{Fe}^{3+}+\mathrm{OH}^{-} \\
& \mathrm{ArRO}_{2} \mathrm{H}+\mathrm{Fe}^{3+} \rightarrow \mathrm{ArRO}_{2}+\mathrm{Fe}^{2+}+\mathrm{H}^{+} \text {. }
\end{aligned}
$$

Итак, основной процесс протекает без непосредственного участия в нем перекиси водорода, которая играет лишь ограниченную роль инициатора, по механизму, присущему вырожденно-разветвленным цепным свободнорадикальным реакциям. Это значит, что вопреки сложившемуся мнению и несмотря на формальное сходство конечных результатов, механизм химически активированного процесса окисления алкил-

\begin{tabular}{|c|c|c|c|c|c|c|}
\hline \multirow{3}{*}{ Показатели } & \multicolumn{3}{|c|}{$\begin{array}{c}\text { Изопропилбензолсуль- } \\
\text { фонат }\end{array}$} & \multicolumn{3}{|c|}{$\begin{array}{l}\text { H-Гептилбензол- } \\
\text { сульфонат }\end{array}$} \\
\hline & \multicolumn{2}{|c|}{$\begin{array}{c}\text { Суммарный } \\
\text { процесс }\end{array}$} & \multirow{2}{*}{$\begin{array}{l}\text { Первая } \\
\text { стадия }\end{array}$} & \multicolumn{2}{|c|}{$\begin{array}{c}\text { Суммарный } \\
\text { процесс }\end{array}$} & \multirow{2}{*}{$\begin{array}{l}\text { Первая } \\
\text { стадия }\end{array}$} \\
\hline & $\begin{array}{l}\text { по кис- } \\
\text { лороду }\end{array}$ & $\begin{array}{l}\text { по рас- } \\
\text { ходу } \\
\text { AAC }\end{array}$ & & $\begin{array}{l}\text { по кис- } \\
\text { лороду }\end{array}$ & $\begin{array}{l}\text { по рас- } \\
\text { ходу } \\
\text { ААС }\end{array}$ & \\
\hline $\begin{array}{l}\text { Порядок реакции } \\
\text { Размерность константы }\end{array}$ & Нулевой & Первый & & Нулев & & \\
\hline $\begin{array}{l}\text { скорости реакции }(\kappa) \\
\text { Множитель при } \kappa \\
\text { Значения } \kappa \text { при темпера- }\end{array}$ & $\begin{array}{c}M / \Omega \cdot c e \kappa \\
10^{-3}\end{array}$ & $\begin{array}{l}c e \kappa^{-1} \\
10^{-6}\end{array}$ & & $\begin{array}{c}M / \Omega \cdot c e x \\
10^{-8}\end{array}$ & & $\begin{array}{c}M / \Omega \cdot c e \kappa \\
10^{-9}\end{array}$ \\
\hline $\begin{array}{cc}\text { Type, }{ }^{\circ} \mathrm{C}: & 40 \\
& 50 \\
& 60 \\
& 70\end{array}$ & $\begin{array}{l}1,18 \\
2,05 \\
3,51 \\
8,08\end{array}$ & $\begin{array}{r}1,38 \\
2,90 \\
7,23 \\
14,70\end{array}$ & $\begin{array}{l}0,15 \\
0,22 \\
0,66 \\
0,90\end{array}$ & $\begin{array}{c}2,04 \\
2,14 \\
4,0 \\
10,60\end{array}$ & $\begin{array}{r}2,35 \\
2,44 \\
4,88 \\
11,35\end{array}$ & $\begin{array}{l}0,41 \\
0,72 \\
0,87 \\
2,06\end{array}$ \\
\hline $\begin{array}{c}\text { Кажущаяся энергия ак- } \\
\text { тивацин, ккал/моль }\end{array}$ & 13,2 & 16,45 & 17,4 & 8,2 & 7,98 & 13,25 \\
\hline
\end{tabular}
арилсульфонатов резко отличается от $\beta$-окисления при их биохимической деградации.

Макрокинетика окисления модельных алкиларилсульфонатов

Изложенные представления о макромеханизме процесса положены в основу его ориентировочной макрокинетической оценки. Последняя дана нами (см. таблицу) интегральному процессу окисления ААС и частной реакции, которая характеризует первую стадию и завершается образованием сложных эфиров. Известную погрешность в результаты расчета вносит приравнивание молекулярного веса всех соединений с кетонными группами к показателю для первичных кетонов.

Суммарный процесс окисления описывается макрокинетическим урав. нением нулевого порядка (исключение составляет случай при использо. ваніни для расчета данных по расходованию органического компонента при окислении изопропилбензолсульфоната). Этот процесс сравнительно слабо стимулируется повышением температуры, особенно для производ- 
ной кумола при достаточно высокой температуре и для высшего гомолога при относительно пониженных температурных уровнях. Қажущаяся энергия активации суммарного процесса, несмотря на применение активирующей добавки, существенно повышена в сравнении с показателями для аутоокисления «материнских» алкилбензолов (15 против 6,6 ккал для кумола и его производной и 8 против 5 ккал для высшего гомолога).

Энергетически наиболее затруднена первая стадия окисления (17 il $13 \kappa \kappa a \Omega)$, в которой скорость деградации снижена в 5-15 раз по сравнению с окислением в суммарном процессе.

Проведенная работа представляет собой первую ступень в создании основы для сопоставления поведения алкиларилсульфонатов разного строения в свободнорадикальных процессах окислительной деградации и оценки влияния структурного фактора на их реакционную способность.

\section{ЛИТЕРАТУ РА}

1. Bishop D. F., Stern G., Fleischmann M., J. and A. Proc. Design and Development, 7, № 1. (1968).

2. При и ман Р., Па альме Л., Гу уергриц М., Изв. АН ӘССР, Хим. Геол., 16, № 1,116 (1967).

3. При им ан Р., Паа льм е Л., Изв. АН ЭССР, Хим. Геол., 17, № 1, 39 (1968).

4. G a dell e G., Contributions à l'étude de l'oxidation en phase liquide par l'oxygène des hydrocarb. aromat. monocycl. substitués, Thèse, Fac. Sci. Université de Paris. 1967.

5. Р едо ш к н Б. А., Исследование жидкофазного окисления некоторых алкилароматических углеводородов и термического разложения гидроперекиси изопропилбензола. Диссертация, Горьковский государственный университет, 1966.

6. S w i s he r R. D., Chem. Engng Progr., 60, 12 (1964).

\section{Ннститут химии \\ Академии наук Эстонской ССР 26jIII 1971 \\ REET PRIIMAN, M. GUBERGRITS \\ ALKOOLARUOLSULFONAATIDE AKTIVEERITUD OKSUDATSIOONI KINEETIKA}

Поступила в редакцию

Käsitletakse isopropüül ja $n$-heptüülbenseen-sulfonaadi initsieeritud oksüdatsiooni molekulaarse hapnikuga kahevalentse rauaiooni ja vesinikperoksiidi juuresolekul.

Reaktsioon algab hüdroperoksiidi moodustumise ja lagunemisega (reaktsioon $A$ ) ning samaaegselt ketooni ning karboksüülhappe tekkimisega (reaktsioon $B$ ). Sügavama destruktsiooniga kaasneb benseenituuma osaline lagunemine ja sulfonaatse grupi eraldumine.

Makrokineetilised arvutused on tehtud reaktsioonide algstaadiumi kohta.

\section{REET PRIIMAN, M. GUBERGRITS}

\section{THE MACROKINETICS OF ALKYLBENZENE-SULPHONATES ACTIVATED OXIDATION}

Two individual alkylbenzene-sulphonates (ABS) activated kinetics of oxidation under an unlimited access of oxygene and admittance of iron salts and perhydrol were studied.

The first stage of the total process is stated to include two simultaneous primary reactions - of the hydroperoxide formation and decomposition (reaction $A$ ) and the ABS direct oxidation into alkylaromatic kenote and carboxylic acid (reaction $B$ ). The second stage of the ABS deeper oxidation is accompanied by a formation of several compounds with carbonyl groups, partial rupture of $\mathrm{C}-\mathrm{C}$ bonds in the aromatic ring and breaking away of the sulphonate group.

The macrokinetic computations are made relative to the total process and its first stage in the case of oxidative degradation of isopropyl- and $n$-heptylbenzene-sulphonates. 